\title{
O HUMANISMO TEÓRICO DE CHE GUEVARA
}

\author{
Caio Martins Bugiato ${ }^{1}$
}

\section{Resumo:}

A polêmica tese de Louis Althusser sobre a ruptura epistemológica na obra de Karl Marx gerou uma série de divergências entre os marxistas nas últimas décadas do século XX. Sua ideia central é a divisão do pensamento de Marx em dois momentos: o jovem Marx, momento no qual o pensamento de Marx estaria inserido na problemática ideológica do humanismo teórico do filósofo Ludwig Feuerbach; e o Marx da maturidade, momento no qual Marx teria fundado a ciência da história e cunhado teses e conceitos para uma nova problemática, o materialismo histórico e dialético. Ideia esta que está em oposição à interpretação sobre uma evolução linear do pensamento marxiano, como se vê em György Lukács. Dessa forma, o objetivo deste texto é, mediante uma análise bibliográfica, resgatar a tese de Althusser sobre a ruptura epistemológica no pensamento de Marx e, à luz desta, interpretar o pensamento de Ernesto "Che" Guevara, um dos líderes da Revolução Cubana de 1959. O pensamento de Che sobre o homem novo de moral socialista desencadeou debates sobre as condições materiais para a transição ao socialismo e fomentou práticas teóricas e concretas no curso inicial da revolução. Assim sendo, tal interpretação sobre as ideias e as práticas de Che nos indica que o seu pensamento está alicerçado no humanismo teórico que envolve o pensamento do jovem Marx.

Palavras-chave: Ruptura epistemológica, Problemática, Humanismo teórico, Karl Marx, Che Guevara.

\begin{abstract}
:
The controversial thesis of Louis Althusser about the epistemological rupture in the work of Karl Marx created several divergences among the Marxists in the last decades of the $20^{\text {th }}$ century. His main idea is the division of Marx's thought into two moments: the young Marx, moment in which his thought would be inserted in the ideological problematic of the theoretical humanism of the philosopher Ludwig Feuerbach; and the Marx of maturity, moment in which Marx would have established the science of history and created thesis and concepts for a new problematic, the historical and dialectical materialism. This idea is opposed to the interpretation about a linear evolution in Marx's thought, as we can see in György Lukács. Therefore, by the aid of bibliographical analysis, the aim of this text is to rescue the thesis of Althusser about the epistemological rupture in Marx's thought and, with this thesis, interpret the thought of Ernesto "Che" Guevara, one of the leaders of the Cuban Revolution in 1959. Che's thought about the new man with a socialist moral unleashed debates about the material conditions for the transition to socialism e promoted theoretical and concrete practices in the beginning of the revolution. Thus, this interpretation about the ideas and practices
\end{abstract}

\footnotetext{
${ }^{1}$ Doutorando em Ciência Política pelo Instituto de Filosofia e Ciências Humanas da UNICAMP. Professor no curso de Relações Internacionais da UNISANTOS e pesquisador do CEMARX/UNICAMP.
} 
of Che indicates that his thought is grounded in the theoretical humanism that involves the thought of the young Marx.

Keywords: Epistemological rupture, Problematic, Theoretical humanism, Karl Marx, Che Guevara.

\section{Introdução}

Este texto é uma leitura dos escritos e discursos de Ernesto "Che" Guevara mediante a perspectiva da tese de Louis Althusser sobre a ruptura epistemológica no pensamento de Karl Marx. A partir dessa leitura é possível identificar nos escritos e discursos de Che elementos do humanismo teórico, problemática na qual o pensamento do jovem Marx está envolvido. Assim, o presente texto foi organizado da seguinte forma: na primeira parte apresentamos a tese de Althusser sobre a ruptura epistemológica no pensamento de Marx, enfatizando os conceitos de problemática e humanismo teórico que compõe essa tese. Ainda nessa primeira parte, apresentamos a interpretação de György Lukács sobre a obra de Marx com a finalidade de contrapor tal interpretação a de Althusser. Pensamos que com essa contraposição o leitor pode ter melhor entendimento da tese de Althusser. Na segunda parte do texto expomos o "pensamento" de Che. Os escritos e discursos de Che estão dispersos em vários meios de divulgação e publicação o que dificulta nosso acesso - e, apesar de alguns deles estarem compilados em coletâneas, recorremos a seus comentadores. Por fim, apresentamos os elementos do humanismo teórico que os escritos e discursos de Che carregam.

\section{Ruptura epistemológica, problemática e humanismo teórico em Althusser.}

Em alguns de seus textos, principalmente em Sobre o Jovem Marx (1979a), Marxismo e humanismo (1979b), Sobre a evolução do jovem Marx (1978) e A querela do humanismo (1999), Louis Althusser defende a tese sobre a ruptura epistemológica no pensamento de Marx. Em linhas gerais, Althusser afirma que existe uma ruptura que divide o pensamento de Marx em dois momentos: o jovem Marx e o Marx da maturidade. Isso significa dizer que até certa etapa de sua vida o pensamento do jovem 
Marx está dentro de uma problemática distinta da problemática que se envolve após a ruptura, a problemática do Marx da maturidade.

Por problemática Althusser entende a estrutura de pensamento cujos elementos têm uma unidade profunda, de modo que tais elementos estruturados condicionam a prática teórica. Em outras palavras, problemática é o conjunto sistematizado de teses, teorias, conceitos, etc., que delimitam o campo no qual o pensador pode pensar. A unidade da problemática é dada pela(s) pergunta(s) que articula(m) o pensamento e sua estrutura condiciona o(s) problema(s) e a(s) resposta(s).

$\mathrm{Na}$ tese da ruptura (ou corte) epistemológica, os escritos do jovem Marx estão na problemática do humanismo teórico de Ludwig Feuerbach. O humanismo teórico de Feuerbach consiste em deparar-se com os problemas colocados pelo idealismo alemão, ou seja, os problemas kantianos fundamentais, mas interpretados pela crítica e pelas soluções hegelianas. A unidade profunda desse humanismo é o conceito fundamental de homem (o que é o homem?), cujos elementos estruturais são as noções de essência humana, emancipação humana e alienação. Essa tríade implica no seguinte problema: existe uma essência humana - o homem comunitário devotado ao congraçamento com seus semelhantes -, que foi alienada, pelo Estado ou pela religião, por exemplo, e dessa forma a emancipação humana significa recuperar a essência humana perdida. Esses elementos são noções porque de acordo com Althusser o humanismo de Feuerbach está no terreno da ideologia, em oposição ao científico. Ideologia esta que significa uma noção pré-científica da realidade, uma ilusão interessada e inconsciente da realidade, cuja função essencial é reproduzir as relações sociais. Assim, o humanismo do jovem Marx pode ser considerado não uma formação teórica, mas sim uma formação para a teoria (científica).

Como Marx opera com o humanismo teórico de Feuerbach em seus escritos de juventude? Dependendo do texto em análise, a resposta a essa pergunta pode ser dada de maneiras diferentes. Isso não quer dizer que Marx está fora da problemática do humanismo teórico, mas que estende tal humanismo a diferentes objetos. "Uma teoria não muda de natureza ao tratar de um objeto suplementar" (Althusser, 1999). Na Crítica à filosofia do direito de Hegel e n'A questão judaica, Marx estende a crítica religiosa à política dentro da teoria feuerbachiana do homem e da alienação. Vejamos o que Althusser (1978 e 1999) nos mostrar ao analisar à luz de sua tese os Manuscritos econômico-filosóficos de 1844. 
Nos Manuscritos, Marx se encontra em um impasse teórico provocado pela extensão da teoria feuerbachiana à economia, mas precisamente à economia de Adam Smith e David Ricardo e todas suas categorias de capital, trabalho, lucro, renda, salário, etc.

\begin{abstract}
Marx consegue, nos Manuscrits de 1844, essa prodigiosa operação teórica de criticar as categorias dos Economistas e a própria Economia Política, submetendo-os aos princípios teóricos do Humanismo feuerbachiano: $\mathrm{O}$ Homem e a alienação. A relação especular Essência do Homem = Essência dos seus Objetos como objetivação de sua Essência, típica do Humanismo feuerbachiano, domina toda a teoria do trabalho alienado. No trabalho, o homem objetiva sua essência (suas forças essenciais, suas forças genéticas) que se exterioriza sob a forma dos produtos de seu trabalho. Por certo, lidamos aqui com uma produção de objetos reais, materiais, e não mais com objetos espirituais como Deus e o Estado. Mas o princípio de alienação permanece o mesmo. Ele atua no seio da relação especular: operário (sujeito)

= seus produtos (seus Objetos), onde o Homem = seu mundo de objetos. Os efeitos que Marx tira dessa aplicação-extensão da teoria feuerbachiana aos objetos da produção econômica e às categorias dos Economistas (que ele tem então por categorias da economia, sem, um só instante, recolocá-las em questão, como o fará em Le Capital) são certamente novos em relação aos discursos anteriores sobre a religião e a política. Mas esses efeitos não tocam os princípios da teoria feuerbachiana do Homem e da alienação, da Essência Genérica do Homem (Marx "reencontra-a", por exemplo, na divisão do trabalho...), por uma boa razão: eles são seu produto direto e necessário. $\mathrm{O}$ "encontro" com a Economia Política (ou melhor, com as categorias dos Economistas) não muda, portanto, nada no dispositivo teórico de Feuerbach [Grifos do autor] (ALTHUSSER, 1999, p. 29-30).
\end{abstract}

Ocorre nos Manuscritos de 1844 igualmente outro evento teórico, que é a tentativa de Marx enxertar no humanismo de Feuerbach categorias de $\mathrm{Hegel}^{2}$. Nos Manuscritos, “a Economia Política e Hegel são seus convidados [de Feuerbach], ele os recebe, apresenta-os um ao outro, explica-lhes que são da mesma família (trabalho), sentam-se e a conversa começa: na casa de Feuerbach" - Grifos do autor (ALTHUSSER, 1999, p. $31)$.

A problemática não qual o jovem Marx está inserido lhe coloca obstáculos epistemológicos que são quebrados com o abandono do humanismo teórico de Feuerbach. Entre muitos aspectos, dois são particularmente importantes para compreender o processo de ruptura com a problemática anterior. O primeiro é a história política de Marx, isto é, o deslocamento da posição política de um jovem intelectual filho da burguesia alemã do liberalismo radical, no tempo da Gazeta Renana (1841-42), para o comunismo. Marx deixa um ambiente dominado pela filosofia idealista alemã, a Prússia, e encontra na França uma classe operária organizada e na Inglaterra uma economia capitalista altamente desenvolvida. Dirigente do movimento comunista

${ }^{2}$ Para uma explicação detalhada, cf. Althusser, 1999, p. 30-33.

\begin{tabular}{|l|l|l|l|l|}
\hline Revista Díalectus & Ano 1 & n. 2 & Janeiro-Junho 2013 & p. 60-69 \\
\hline
\end{tabular}


internacional, Marx percebe que a história das sociedades é a história da luta de classes e empenha-se em demonstrar os mecanismos de exploração e dominação de classe. $\mathrm{O}$ segundo aspecto é a história teórica de Marx, que não pode ser contada sem o pano de fundo da história política. A trajetória teórica de Marx vai de um pensamento ocupado por concepções ideológicas (pré-científicas) à ciência da história ou à ciência da história das formações sociais (o que é história?). O pensamento de Marx passa de uma filosofia da história, com saber definitivo e absoluto, um sistema fechado em si, sem desenvolvimento para produzir novos conhecimentos e sem objeto no sentido científico à fundação de uma nova ciência. É uma descoberta revolucionária, produzida pela conjunção da filosofia alemã, da economia política inglesa e do socialismo francês (o que Lênin chama de as três fontes ou as três partes constitutivas do marxismo) numa conjuntura determinada: as lutas de classes impulsionadas pelo desenvolvimento de capitalismo na Europa.

Althusser (1999) reconhece que ainda é pouco estudado o processo de produção da ruptura epistemológica. Entretanto, afirma que este tem início com a declaração de ruptura nas Teses sobre Feuerbach e n'A ideologia alemã e seu processo de consumação se dá nos anos que separam $A$ ideologia d'O capital. Processo que pode ser apreendido pelo advento de conceitos da nova ciência ${ }^{3}$. Assiste-se, então, à gênese dos inéditos conceitos de forças produtivas, relações de produção, modo de produção, formação social, infraestrutura, superestrutura, Estado, classes sociais, luta de classes, etc. Dado que não há relação de continuidade entre os sistemas de conceitos marxistas e o sistema das noções pré-marxistas, Althusser (1978) conclui que o pensamento de Marx está numa nova problemática, o materialismo histórico e dialético: "não se pode dizer absolutamente que a juventude de Marx pertence ao marxismo" [Grifos do autor] (ALTHUSSER, 1979a, p. 71). A essa diferença teórica, Althusser (1978) dá o nome de ruptura epistemológica.

A tese de ruptura epistemológica de Althusser é também um método de como ler obra de Marx. Ao mesmo tempo, critica o método analítico-teleológico de ler a obra de Marx. Este método permite pensar elementos de um sistema de forma isolada, sem levar em consideração o contexto no qual foram produzidos; considera elementos isolados, produzidos em estruturas diferentes, como iguais ou semelhantes (exemplo: o conceito

\footnotetext{
${ }^{3}$ Althusser (1999) aponta a importância da publicação da obra de Stirner, L'unique et sa propriété, em 1845, entre as publicações dos Manuscritos de 1844 e d' A ideologia em 1846. Segundo Althusser, essa obra de Stirner serviu para desagregar categorias que permeavam o pensamento do jovem Marx.
} 
de proletariado no Manifesto do partido comunista e na Crítica à filosofia do direito de Hegel). O método analítico-teleológico aplicado à obra de Marx é uma decomposição "provocada precisamente pelas leituras dos textos da juventude através do conteúdo dos textos da maturidade" (ALTHUSSER, 1979a, p. 46).

O método analítico-teleológico é empregado por György Lukács para interpretar a obra de Marx. Lukács (2009) extrai à força dos textos do jovem Marx conceitos que estão nas obras de maturidade. Vejamos:

\begin{abstract}
ele [Marx] aponta para distinção fundamental entre a emancipação política e a emancipação humana: a primeira é apenas um progresso no interior "do atual ordenamento do mundo", enquanto a segunda, a emancipação humana, pressupõe, ao contrário, a negação da "auto-alienação humana" e, portanto, um ordenamento fundamentalmente novo da sociedade. Ainda que inicialmente na terminologia do "humanismo real" de Feuerbach, Marx expressa aqui a oposição entre os resultados da revolução burguesa e da revolução socialista; deste modo, ele chega ao terreno a partir do qual podem ser reveladas as contradições internas da sociedade burguesa. (...) Marx anuncia, aqui, com toda clareza, a compreensão de que a emancipação política (ou seja, a revolução burguesa) cria apenas uma democracia formal, que proclama direitos e liberdades que não podem existir realmente na sociedade burguesa (LUKÁCS, 2009, p. 165-167).
\end{abstract}

Nessa passagem Lukács comparando os conceitos de emancipação política e emancipação humana presentes n'A questão judaica de 1843 com os conceitos de revolução burguesa e revolução socialista presentes (não apenas) nas obras históricas de Marx ${ }^{4}$, identifica que estes conceitos estão em estágio embrionário naquele texto. Lukács interpreta o pensamento de Marx como se fosse uma evolução teórica, isto é, os novos conceitos de que fala Althusser estariam sendo produzidos já na problemática humanista na qual está o pensamento do jovem Marx.

\begin{tabular}{|l|l|l|}
\multicolumn{2}{c}{ Jovem Marx } & Marx da maturidade \\
\hline Emancipação política & >evolução> & Revolução burguesa \\
\hline Emancipação humana & >evolução> & Revolução socialista \\
\hline
\end{tabular}

Fonte: elaboração própria

Para Lukács (2009), não há mudança de problemática, não há ruptura; existe um caminho intelectual percorrido, cujo trajeto é o desenvolvimento de germes já contidos nas etapas iniciais. O método analítico-teleológico de Lukács pode ser igualmente percebido pelos termos que o autor utiliza para se referir à trajetória intelectual de Marx: evolução, desenvolvimento, aperfeiçoamento, amadurecimento, germe, embrião, entre outros. Sob a luz da tese de Althusser, é impossível derivar um conceito novo de um

\footnotetext{
${ }^{4}$ As lutas de classe na França de 1848 a 1850, de 1850; O 18 Brumário de Luis Bonaparte, de 1852 e A guerra civil na França, de 1871.
}

\begin{tabular}{|l|l|l|l|l|}
\hline Revista Dialectus & Ano 1 & n. 2 & Janeiro-Junho 2013 & p. 60-69 \\
\hline
\end{tabular}


conceito presente em um texto de juventude de Marx, uma vez que eles estão em problemáticas distintas e separados por uma ruptura. Ademais, este método que Lukács emprega dissimula a obra de Marx e pode ter consequências na prática política.

\section{O homem novo de Che Guevara.}

Ernesto "Che" Guevara foi um dos líderes do processo que culminou na tomada do aparato estatal pelos guerrilheiros da Sierra Maestra em 1959, a conhecida Revolução Cubana. A revolução expropriou o capital estrangeiro da ilha e a partir de então seus dirigentes se dedicaram a implementar a planificação socialista na economia cubana. Che estava à frente desse processo como presidente do banco nacional e ministro da indústria na primeira metade da década de 1960. Desse modo, no campo teórico, Che e outros marxistas travaram um debate que foi publicado em revistas da época e ficou conhecido como El gran debate economico en $\mathrm{Cuba}^{5}$.

Existe uma questão fundamental nesse debate que é particularmente interessante para nossa investigação neste texto: a questão dos estímulos materiais e morais na construção do socialismo. Che era um defensor da preponderância dos estímulos morais. Ele via a possibilidade de incentivar a produção dos trabalhadores por meio de estímulos não materiais. Tais estímulos cumpririam o papel de formar um espírito de coletividade e uma consciência da importância de cada trabalhador na construção do socialismo. Prêmios como bônus, medalhas, diplomas, etc. seriam valorizados em todo o país e levariam outros a seguir o exemplo dos trabalhadores consagrados. Vale resaltar que naquele momento Cuba passava por uma dura escassez material e financeira. Nessa questão, Che dialogava principalmente com Charles Bettelheim, o qual defendia preponderância dos estímulos matérias, ou seja, incentivar a produção por meio de estímulos materiais como aumento de salário por produtividade, pagamento de horaextra, etc. Che via nos estímulos materiais um resquício do capitalismo que deveria ser eliminado para não fomentar o individualismo, o egoísmo e grupos elitistas, enquanto Bettelheim via em tais estímulos um elemento do passado capitalista, mas ainda necessário no período de transição.

Não foi apenas nesse debate econômico que Che ressaltou a importância dos estímulos morais na construção da sociedade socialista. Em vários escritos, entrevistas,

\footnotetext{
${ }^{5}$ Este debate foi publicado em 2004: GUEVARA, Ernesto Che [et al.].El gran debate sobre la economía en Cuba, 1963-1964. 2. ed. La Habana: Ed. de Ciencias Sociales, 2004.
}

\begin{tabular}{|l|l|l|l|l|}
\hline Revista Dialectus & Ano 1 & n. 2 & Janeiro-Junho 2013 & p. 60-69 \\
\hline
\end{tabular}


discursos nos países por onde passou, Che defendera explicita ou implicitamente o que pode ser chamado de homem novo, isto é, o homem socialista, movido pelos estímulos morais socialistas e pela ética socialista. Para Che, o pressuposto para a construção de uma nova sociedade era a construção do homem novo. Construção esta que se daria por meio da educação.

Corre-se o perigo de que as árvores impeçam de ver o bosque. Perseguindo o sonho de realizar o socialismo por meio das armas ineficientes que o capitalismo nos legou (a mercadoria como celula mater da economia, a rentabilidade, a cobiça material e individual como barreira, etc.), se pode chegar a um beco sem saída. E chega-se ali depois de percorrer uma longa distancia, na qual os caminhos se entrecortam várias vezes e onde é difícil perceber o momento em que se tomou o caminho errado. Entretanto, a base econômica adaptada consumou seu trabalho de destruição do desenvolvimento da consciência. Para construir o comunismo em simultaneidade com a base econômica é preciso criar o 'homem novo'. (GUEVARA apud BANDERA, 1998, p. 87).

Che estava convicto que a estratégia deveria ser construída pelo homem novo, de moral socialista/comunista e consciência coletiva na sociedade de transição. Daí ter sido Che um fervoroso fomentador do trabalho voluntário, do qual participou com assiduidade na qualidade de cidadão comum. Em um discurso a União da Juventude

Comunista, ele afirmou:

Esta é a forma de educação mais apropriada para a juventude que se prepara para o comunismo: a forma de educação no qual o trabalho perde a conotação de obsessão que possui no mundo capitalista e passa a ser um grato dever social, que se realiza com alegria, ao som das canções revolucionárias, em meio à camaradagem mais fraternal, nos contatos humanos que revigoram uns e outros e que a todos eleva (GUEVARA, 1986, p. 52).

A moral socialista/comunista deveria ser alcança antes de se atingir a sociedade comunista, pois é essa moral o elemento edificador de tal sociedade e não as condições objetivas do desenvolvimento das forças produtivas na ditadura do proletariado. Che pensava que a grande contribuição do marxismo era a subjetividade revolucionária.

\footnotetext{
O socialismo econômico não me interessa sem a moral comunista. Lutamos contra a miséria mas, ao mesmo tempo, lutamos contra a alienação. Um dos objetivos fundamentais do marxismo é fazer desaparecer o interesse, o fator 'interesse individual' e o 'proveito próprio', das motivações psicológicas. ( ) Marx se preocupava tanto com os acontecimentos econômicos como com sua tradução pela mente humana. Ele chamava isso de "atos de consciência". Se o comunismo descuidar dos atos de consciência pode até ser um método de distribuição de bens mas deixa de ter uma moral revolucionária (GUEVARA apud BANDERA, 1998, p. 88).
}

Michael Löwy (1976), interpretando os escritos de Che, afirma que o guerrilheiro teria compreendido melhor o caráter humanista das obras de Marx, sem se contrapor à ciência. Para Löwy (1976), o homem novo de que Che falava deve ser um 
homem mais responsável e rico interiormente, ligado a outros homens por um vínculo de solidariedade real e de fraternidade universal; um homem que, uma vez quebrados os grilhões da alienação, reconhece-se na sua própria obra, seu trabalho; um homem que atingirá a consciência plena de seu ser social e sua total realização com criatura humana. "Um homem cuja condição de possibilidade é o que Marx chamava, nas Teses sobre Feuerbach, a humanidade socializada" (LÖWY, 1976, p. 38). Raul Fornet-Betancourt também analisando os escritos de Che conclui que "o humanismo do novo homem significa, para Guevara, progresso no curso daquela dialética da emancipação que, exatamente, é libertadora porque é executada pelo homem concreto na sua situação histórica” (FORNET-BETANCOURT apud PERICÁS, 1998, p. 97).

\section{Considerações finais}

A questão sobre o homem novo ou novo homem não surgiu pela primeira vez no marxismo com Che. Em Marx, Engels, Lenin e Mao-Tsé Tung já havia discussões sobre o caráter do homem em uma sociedade pós-capitalista, sobre seus valores, conduta e consciência. Che, na situação em que Cuba se encontrava de escassez material e financeira na década de 1960, retomou essa discussão e propôs como prática política, isto é, a criação no homem novo como política de um Estado revolucionário.

Teriam, então, as condições socioeconômicas de Cuba impelido Che a adotar a política de criação do homem novo? Pensamos que não. Porque nossa análise indica que o "pensamento" de Che está permeado pelo humanismo. Não o humanismo teórico feuerbachiano ipsis litteris, mas um humanismo que carrega elementos dele. Vejamos. A tríade conceitual do humanismo feurbachiano pode ser elencada como essência humana, emancipação humana e alienação, cujo problema principal é: essência humana foi alienada - no caso, pelo capitalismo -, então, é necessário recuperar a essência humana alienada. É nessa tríade conceitual que o pensamento do jovem Marx está envolvido, o qual por sua vez é base para do "pensamento" de Che. Essência humana, alienação e emancipação humana permeiam o "pensamento" de Che. Pare ele, os homens estão alienados, sua consciência foi destruída pelo capitalismo, que torna o trabalho dos homens uma obrigação dispendiosa na qual os homens não se reconhecem. Dessa forma, é necessário lutar contra essa alienação - um dos objetivos fundamentais do marxismo -, construindo o homem novo, homens conscientes e com novos valores morais, que emancipar-se-ão da base econômica capitalista, converterão o trabalho num

\begin{tabular}{|l|l|l|l|l|}
\hline Revista Dialectus & Ano 1 & n. 2 & Janeiro-Junho 2013 & p. 60-69 \\
\hline
\end{tabular}


grato dever social e construirão a sociedade comunista. Em linhas gerais, esse é o "pensamento" de Che, que expusemos no item anterior. Um pensamento que se assemelha muito ao do jovem Marx quando escreve os Manuscritos de 1844. Che não dissociava a moral socialista/comunista da realidade do desenvolvimento material, mas apostou a maioria de suas fichas na construção dessa moral. É provável que essa aposta/prática política tenha trazido consequências para a revolução cubana. Entretanto, dado os limites da discussão teórica desse texto, deixamos essa análise para outra oportunidade.

\section{Referências Bibliográficas}

ALTHUSSER, Louis. A querela do humanismo. In: Crítica Marxista, n. 09. São Paulo: Xamã, 1999.

. Marxismo e Humanismo. In: A favor de Marx. Rio de Janeito: Zahar Editores. 1979b. Sobre a evolução do jovem Marx. In: Posições -1. São Paulo: Graal, 1978.

Sobre o jovem Marx. In: . A favor de Marx. Rio de Janeito: Zahar Editores. 1979a.

BANDERA. Vinicius. O debate econômico dos anos 60. In: COGGIOLA, Osvaldo (org.). Revolução Cubana: história e problemas atuais. São Paulo: Xamã, 1998.

GUEVARA, Ernesto Che [et al.]. El gran debate sobre la economía en Cuba, 19631964. $2^{a}$ Ed. La Habana: Ed. de Ciencias Sociales, 2004.

GUEVARA, Ernesto Che. Escritos econômicos. In: Cuadernos de Pasado y Presente 5. Cordoba: Ediciones Pasado y Presente, 1969.

.Obras completas. Tomo 2. Buenos Aires: Ediciones Argentinas, 1973.

. Textos políticos. $3^{\text {a }}$ Ed. São Paulo: Global Editora, 1986.

LÖWY, Michael. O pensamento de Che Guevara. Lisboa: Bertrand, 1976.

LUKÁCS, György. O jovem Marx e outros escritos de filosofia. UFRJ: Rio de Janeiro, 2009.

PERICÁS, Luiz Bernardo. Che Guevara e o homem novo. In: COGGIOLA, Osvaldo (org.). Revolução Cubana: história e problemas atuais. São Paulo: Xamã, 1998. 